\title{
um passado que não passa: a
persistência do crime de tortura na democracia brasileira
}

\author{
Caroline Silveira Bauer*
}

Este artigo tem como objetivo apresentar alguns resultados de uma pesquisa que tinha por objetivo analisar a continuidade do crime de tortura da ditadura civil-militar aos dias de hoje. Para tanto, a investigação estruturou-se nos seguintes eixos: a prática da tortura durante a ditadura civil-militar brasileira (1964-1985), a existência da tortura após 1985 e a análise dos aspectos de continuidade existentes entre o período autoritário e a democracia.

Palavras-chave: Tortura; Ditadura civil-militar brasileira; Democracia.

Abstract: This paper aims to examine the continuity of the crime of torture from civil-military dictatorship up today. Therefore, the research was structured in the following areas: the use of torture during Brazilian civil-military dictatorship (1964-1985), the existence of torture after 1985 and the analy-

\section{Atortura durante a ditadura civil-militar}

A prática da tortura na história brasileira não se inicia com a instauração da ditadura civil-militar em 31 de março de 1964, embora seu uso como forma de obtenção de informações, punição e disseminação do medo tenha sido empregado desde as primeiras horas do golpe. A partir dessa data, a tortura se

\footnotetext{
* Doutora em História pela UFRGS e Universitat de BarcelonaDepartamento de História/ UFPel carolinebauer@gmail.com
} 
sis of aspects of existing continuity between the authoritarian period and democracy.
Keywords: Torture; Brazilian civil-military dictatorship; Democracy.

transforma em parte da metodologia repressiva do Estado - a estratégia de implantação do terror $-^{1}$, tendo sido aprimorada com cursos que a elevaram à matéria científica em academias de forças de segurança civis e militares, nacionais e internacionais. $\mathrm{O}$ ineditismo de sua aplicabilidade, neste período, reside, além da cientificidade e da incorporação às práticas estatais, no envolvimento direto das Forças Armadas nos crimes de tortura.

Pela primeira vez na história,

[...] as Forças Armadas envolviam-se profundamente na tortura de presos políticos e na execução de operações militares de repressão à população interna. Isto representa uma série ameaça institucional às Forças Armadas e à sua imagem, até então associada a seu papel na defesa do país contra a agressão externa. ${ }^{2}$

As técnicas desenvolvidas ou aprimoradas durante a ditadura foram apresentadas em aulas práticas, nas quais presos políticos eram utilizados como "cobaias", à exemplo do que ocorreu na Polícia do Exército do antigo Estado da Guanabara, em 1969, onde "mais de 100 (cem) sargentos e cujo professor era um oficial da PE [Polícia do Exército], chamado Ayton"3, assistiram filmes e projeção de slides sobre técnicas de tortura ${ }^{4}$, que eram demonstradas ao com esses presos políticos. ${ }^{5}$ Além disto, as sessões de

\footnotetext{
${ }^{1}$ Por estratégia de implantação do terror entende-se o conjunto de práticas adotadas pelo aparato repressivo da ditadura para a promoção e disseminação do medo na sociedade, formando a "cultura do medo". Essas práticas implicam o sequestro, como forma de detenção; a tortura física e psicológica, como forma de obtenção de informações e de punição; e a morte e a desaparição, como políticas de extermínio. Para maiores informações, cf. BAUER, Caroline Silveira. Brasil e Argentina: ditaduras, desaparecimentos e políticas de memória. Porto Alegre: Medianiz, 2012.
}

${ }^{2}$ ALVES, Maria Helena Moreira. Estado e oposição no Brasil (1964-1984). Bauru: Edusc, 2005. p. 207.

${ }^{3}$ BRASIL: Nunca Mais, v. 1, p. 310.

${ }^{4}$ Idem, p. 183.

${ }^{5}$ Idem, p. 201. 
interrogatório costumavam ser acompanhadas por profissionais da área da saúde, que estabeleciam os limites da prática para a preservação da vida enquanto ela fosse interessante à ditadura. Após a morte da vítima, médicos assinavam falsos atestados de óbito e laudos necrológicos, onde a causa mortis mais apontada era "morto em confronto com as forças de segurança", ocultado a morte por tortura ou execução.

A prática da tortura, um método arbitrário e ilegal, porém legítimo, pressupôs realização de um intenso trabalho ideológico com os agentes dos órgãos de informação e inteligência, a fim de lhes tornar aptos em exercer o terror físico ou psicológico sem remorsos, pelo contrário, com senso de dever. De promotores da "segurança nacional" deveriam converter-se, também, em manipuladores da insegurança, através de um doutrinamento realizado com base na insegurança, no medo e no ódio ${ }^{6}$; tratava-se, em outras palavras, de convertê-los em "operários da violência"7. O trabalho ideológico visava, assim, separar a ação da consciência, o ato do julgamento moral, o indivíduo do senso de responsabilidade, e fazer com que o sujeito introjetasse a ideia de que está tão-somente obedecendo a uma ordem.

Durante os 21 anos da ditadura, a tortura esteve presente cotidianamente - e não apenas como "casos isolados" ou "excessos" - no aparato repressivo, atingindo presos políticos e comuns, não obstante os acordos e as declarações internacionais ratificados pelo Brasil, como a Declaração Universal dos Direitos Humanos, que estabelece em seu artigo quinto que "ninguém será submetido à tortura nem a penas ou tratamentos cruéis, desumanos ou degradantes." O Estado brasileiro subverteu suas obrigações em relação à proteção das liberdades individuais e à promoção do bem comum, pois adquiriu os contornos de um Estado terrorista, fundamentado ideologicamente na Doutrina de Segurança Nacional.

${ }^{6}$ FAÚNDEZ, Héctor. A linguagem do medo: dinâmicas coletivas da comunicação sob o terror no Chile. In: RIQUELME U., Horacio (ed.). Era de névoas: direitos humanos, terrorismo de Estado e saúde psicossocial na América Latina. São Paulo: EDUC, 1993. p. 78.

${ }^{7}$ HUGGINS, Martha; HARITOS-FATOUROS, Mika; ZIMBARDO, Philip. Operários da Violência: policiais torturadores e assassinos reconstroem as atrocidades brasileiras. Brasília: UnB, 2006. 
A luz da Segurança Nacional, a tortura não decorre apenas do sadismo dos torturadores; ela é parte integrante do sistema repressivo montado pelo Estado, a fim de sufocar os direitos e as liberdades de seus opositores. É parte da estratégia de manutenção do poder. Acreditando em sua eficácia e rapidez, as investigações policiais e militares passaram a adotá-la como método exclusivo de apuração de fatos considerados crimes contra a segurança nacional. Para tanto, a tortura tornou-se matéria de estudo teórico e prático em academias militares e centros de instrução policial. ${ }^{8}$

A institucionalização e racionalização da tortura foram realizadas paralelamente à construção de um sofisticado aparato repressivo, que contou com órgãos existentes previamente e outras inovações civis e militares, configurando-se como a maior e mais detalhada organização repressiva do Cone Sul. Nas palavras do coronel Adyr Fiúza de Castro, um dos criadores do Centro de Informações do Exército (CIE),

[...] quando decidimos colocar o Exército na luta contra a subversão [...], foi a mesma coisa que matar uma mosca com um martelo-pilão. Evidentemente, o método mata a mosca, pulveriza a mosca, esmigalha a mosca, quando, às vezes, apenas com um abano é possível matar aquela mosca ou espantá-la. E nós empregamos um martelo-pilão ${ }^{9}$

Estes locais se converteram em legítimos centros de tortura com elevada sofisticação técnica, como o desenvolvimento da cela conhecida como "geladeira", totalmente isolada térmica e sonoramente.

A temperatura pode ser controlada eletronicamente, variando de graus inferiores à zero a temperaturas extremamente quentes. Também eletronicamente podem introduzir-se na cela diferentes sons em tonalidades diversas. O uso alternado de luzes fortes e total escuridão completa o quadro de desagregação física e psicológica do preso. ${ }^{10}$

Além da estrutura legal de repressão, a ditadura contava com uma estrutura paralela, onde grupos paramilitares, como o "Comando de Caça

\footnotetext{
${ }^{8}$ BRASIL: Op. cit., p. 11

${ }^{9}$ D'ARAÚJO, Maria Celina et. al. Os anos de chumbo: a memória militar sobre a repressão. Rio de Janeiro: Relume-Dumará, 1994. p. 75.
}

${ }^{10}$ ALVES, Maria Helena Moreira. Op. cit., p. 204. 
aos Comunistas" ou o "Esquadrão da Morte", sequestravam opositores e os encaminhavam para centros clandestinos de detenção, como a "Casa da Morte", em Petrópolis, Rio de Janeiro, o que contribuía para o sentimento de medo e desproteção daquela vítima. Somente depois de conseguidas as informações iniciais - mediante tortura - tão importantes para a consecução das ordens de busca e apreensão, o sequestrado tinha sua prisão legalizada ao ser entregue a algum órgão do aparato repressivo.

A tortura não foi aplicada somente em militantes de organizações clandestinas, mas também aos opositores políticos em todos os graus, identificados como "inimigos, "subversivos" e "terroristas" - um outro -, o que evidencia o terror ideológico e seu objetivo de destruir ou neutralizar determinados grupos. Primeiramente, as definições são mais restritivas e a repressão acaba atingindo um círculo mais limitado de opositores; posteriormente, esses conceitos tornam-se mais permeáveis e o aparato repressivo passa a combater um número maior de dissidentes.

E assim, em uma espiral ascendente, o Estado autoritário desencadeia uma guerra com objetivos cada vez mais mal definidos, desencadeando golpes contra grupos inofensivos da sociedade, e a imoderação começa a afetar a família e os amigos do "inimigo", o cidadão "neutro", e assim por diante, até que no final, a figura do suspeito está por todos os lados. ${ }^{11}$

Torna-se evidente uma tentativa de desumanização e reificação dos opositores da ditadura civil-militar, um criminoso que existe antes mesmo de haver cometido qualquer crime, "sujeitos sem direito". ${ }^{12}$ Cotidianamente, esses grupos eram apresentados aos funcionários dos órgãos de informação e repressão como dotados “de uma força demoníaca, contra quem não

\footnotetext{
11 "And so, in an ascending spiral, the authoritarian state unleashes a war on objectives ever more ill-defined, dealing blows against anodyne groups of society, as when its immoderation begins to affect the family and friends of the 'enemy', the 'neutral' citizen, and so on, until in the end the figure of the 'suspicious person' appears on all sides." TORRES-RIVAS, Edelberto. Epilogue: notes on terror, violence, fear and democracy. In: KOONINGS, Kees; KRUIJT, Dirk. Societies offear: the legacy of Civil War, Violence and Terror in Latin America. London: Zed Books, 1999. p. 290.

${ }^{12}$ Para maiores informações sobre este conceito de Giorgio Agamben, cf. AGAMBEN, Giorgio. Estado de exceção. São Paulo: Boitempo: 2007.
} 
adiante querer combater ou controlar, mas impõe-se destruir, para que assim, e só assim, seja garantido o bem-estar da sociedade"13. A violência da linguagem empregada para designar o outro desperta sentimentos de medo e paranoia na sociedade, o que poderia levar a uma disposição à violência como recurso legítimo.

Ainda que setores oposicionistas à ditadura soubessem de seu emprego durante os interrogatórios - a ditadura negasse as denúncias que romperam com a censura -, o conhecimento social sobre a prática sistemática da tortura pelos órgãos de informação e segurança ocorreu somente no final da década de 1970, com um abrandamento da censura, o retorno de banidos e exilados, e a publicação de obras memorialísticas de ex-presos e perseguidos políticos sobre a sua experiência do terrorismo de Estado.

A partir do momento em que não se pôde mais negar sua existência, os militares brasileiros passaram a justificar seu emprego, afirmando que no Brasil houve "casos isolados", "excessos" ou "práticas que não se caracterizam como tortura" - que sequer foram apurados no momento do cometimento do crime, demonstrando a conivência e a omissão. Contudo, a tortura jamais foi admitida como política sistemática do regime. Comparando os resultados da ditadura civil-militar brasileira com o caso argentino, onde organizações de direitos humanos contabilizam 30 mil mortos e desaparecidos, o general-de-exército Leônidas Pires Gonçalves relativiza:

\footnotetext{
Mas guerra suja nesse país nunca houve. Nós sempre os enfrentamos da maneira mais denotada e mais corajosa. Aqui não morreram os trinta mil que se diz que morreram na Argentina. Nós nunca perdemos uma guerra. Portanto, não admito que ninguém, nem a sociedade, nem o governo brasileiro, queira punir as Forças Armadas como tem sido demonstrado nos últimos anos. [...] Defendemos, com a maior convicção e denodo, o que pensávamos que era correto. E o número de mortos foi até econômico, do ponto de vista de um país que tem essa população toda. ${ }^{14}$
}

\footnotetext{
${ }^{13}$ MAGALHÃES, Marionilde Dias Brepohl de. A lógica da suspeição: sobre os aparelhos repressivos à época da ditadura militar no Brasil. Revista Brasileira de História, São Paulo, v. 17, n. $34,1997$.
}

${ }^{14}$ D'ARAÚJO, Maria Celina et. al. Op. cit., p. 245-246. 
A mais contundente divulgação do cometimento do crime de tortura durante a ditadura deu-se com a publicação do livro "Brasil: Nunca Mais" em 1985. Tratou-se de um projeto que, utilizando a possibilidade de advogados de presos políticos poderem permanecer 24 horas com os autos do processo, utilizou este tempo para fotocopiar os 707 processos que chegaram ao Supremo Tribunal Militar - lembrando que, desde a promulgação do Ato Institucional n. 2, os chamados "crimes contra a segurança nacional" possuíam fórum militar, mesmo para civis. No total, 1.843 presos e perseguidos políticos que foram implicados em processos junto às Auditorias Militares denunciaram as torturas físicas e psicológicas que haviam sofrido e as que foram vítimas seus companheiros no momento do depoimento perante o juiz, resultando em 2.847 páginas de relatos de 6.016 tipos de torturas ${ }^{15}$, que foram sintetizados no livro. É importante destacar que a pesquisa em que se baseou o livro tem um universo de análise documental bastante restrito, como afirmado acima - somente os processos que chegaram ao Supremo Tribunal Militar -, e, desta forma, não abrange todos os casos de tortura que existiram no Brasil durante a ditadura, impossíveis de serem quantificados.

Com a disponibilização de alguns fundos documentais dos órgãos de informação e repressão da ditadura, teve-se acesso a um documento chamado "Manual do Interrogatório", uma publicação oficial do Centro de Inteligência do Exército datada de 1971 distribuída aos Departamentos de Ordem Política e Social pelo Serviço Nacional de Informações. A origem do material, conforme nota introdutória, corresponde a "uma tradução adaptada de documentação sigilosa de país amigo"16. Por questões de segurança, e, segundo o próprio documento, "por acordo entre governos", "seu manuseio deve respeitar as prescrições do RSAS [Regulamento para Salvaguarda de Assuntos Sigilosos] no tocante à classificação recebida. São proibidas as cópias"17.

\footnotetext{
${ }^{15}$ BRASIL: Nunca Mais, v. 1, p. 17.

${ }^{16}$ Manual do Interrogatório. História: Questões \& Debates, Curitiba, n. 40, 2004. Editora UFPR. p. 203.

${ }^{17}$ Idem.
} 
O general-de-divisão João Carlos Rotta afirmou que a tradução e adaptação de manuais estrangeiros para utilização no Brasil era uma prática comum, utilizando-se no "combate ao terrorismo" "métodos empregados em outros países, como Estados Unidos, Portugal e França. Limitamo-nos a traduzir os manuais existentes e aplicar, naquilo que era possível, a doutrina preconizada"18

Mesmo que a origem do "Manual do interrogatório" não possa ser determinada, seu conteúdo apresenta muitas semelhanças com o "Kubark Counterintelligence Interrogation”, de julho de 1963, uma publicação secreta da Central Intelligence Agency (CIA), utilizada em cursos de inteligência ministrados na Escola das Américas, no Panamá. ${ }^{19}$

O "Manual” oferecia subsídios para a obtenção da confissão de presos através da coerção física e psicológica. Além disto, permite constatar o trabalho ideológico que era feito nos interrogadores para que desempenhassem de maneira produtiva suas funções.

A tortura pode ser entendida como uma situação-limite, pois gera um trauma devido à intensidade das agressões físicas e psíquicas, representando uma ameaça à vida frente à impotência e à passividade diante do torturador ${ }^{20}$. O objetivo é a "quebra" do indivíduo, sua total rendição à condição e à insegurança gerada pela experiência. Em relação às mulheres, muitas abortaram devido às torturas com conotações sexuais. Quanto às faixas etárias dos grupos atingidos pela prática da tortura, tratou-se de um

\footnotetext{
${ }^{18}$ MOTTA, Aricildes de Moraes (coord.). 1964 - 31 de março: o movimento revolucionário e sua história. Tomo 8: Rio Grande do Sul. Rio de Janeiro: Biblioteca do Exército Editora, 2003. p. 151-152.

${ }^{19}$ Uma cópia desse material foi traduzida para o espanhol pela equipe de Direitos Humanos Nizkor e encontra-se disponível em http://www.derechos.org/nizkor/la/libros/soaMI/index. html. O original pode ser consultado em http://www.gwu.edu/ nsarchiv/NSAEBB/NSAEBB27/01-01.htm. Último acesso: 26 abr. 2010.

${ }^{20}$ SALIMOVICH, Sofia, LIRA, Elizabeth, WEINSTEIN, Eugenia. Victims of fear: the social psychology of repression. In: CORRADI, Juan E., FAGEN, Patricia Weiss, GARRETÓN, Manuel Antonio (eds.). Fear at the edge: state terror and resistance in Latin America. Berkeley: University of California Press, 1992. p. 78.
} 
método utilizado em bebês, crianças e adolescentes. Mesmo que estivessem resguardados por tratados e disposições internacionais que protegem a população civil não-combatente em conflitos e guerras, a ditadura, através da tortura física e psicológica, desenvolveu inúmeras formas de agressão à infância e adolescência ${ }^{21}$. Do universo de análise abrangido pelo Brasil: Nunca Mais, há o registro de que catorze menores de 18 anos foram vítimas de algum tipo de tormento ${ }^{22}$.

A prática mais comum utilizada pela ditadura foi o choque elétrico. Fios condutores eram amarrados ou instrumentos eram utilizados em várias partes do corpo da vítima, preferencialmente nas mais sensíveis, como língua, órgãos genitais e ouvidos. O choque provocava queimaduras na pele, e poderia levar a desmaios e convulsões. Seus efeitos a curto e longo prazo variavam desde a necrose da região que estava em contato com a corrente elétrica, até micro hemorragias cerebrais, que poderiam ocasionar distúrbios de memória, diminuição da capacidade cognitiva e até mesmo a mor$\mathrm{te}^{23}$. Os choques eram utilizados conjuntamente ao "pau-de-arara" - suspensão da vítima por uma barra transpassada pelo vão criado pelos joelhos flexionados -, e de uma maneira mais tecnicista através da "cadeira-do-dragão", uma cadeira com placas metálicas eletrizadas, onde a pessoa era colocada amarrada, nua e molhada, para potencializar os efeitos do choque.

Um opositor da ditadura preso em 1976 descreveu, em seu auto de qualificação e interrogatório perante a Justiça Militar, sua experiência de tortura:

[...] sentou-se numa cadeira conhecida como cadeira do dragão, que é uma cadeira extremamente pesada, cujo assento é de zinco, e que na parte posterior tem uma proeminência para ser introduzido um dos terminais da máquina de choque chamado magneto; que, além disso, a ca-

\footnotetext{
${ }^{21}$ MARTÍNEZ, Victoria, PECHMAN, Marta, MARCIANO, Mónica. "É bom ser grande?" Diferentes momentos no tratamento de filhos de desaparecidos. In: RIQUELME U., Horacio (ed.). Era de névoas: direitos humanos, terrorismo de Estado e saúde psicossocial na América Latina. São Paulo: EDUC, 1993. p. 72.
}

${ }^{22}$ BRASIL: $O p$. cit., p. 14.

${ }^{23}$ ARQUIDIOCESE de São Paulo. Brasil: Nunca mais. Petrópolis: Vozes, 1985. p. 47. 
deira apresentava uma travessa de madeira que empurrava as suas pernas para trás, de modo que a cada espasmo de descarga as suas pernas batessem na travessa citada, provocando ferimentos profundos; $[\ldots]^{24}$

A experiência de situações de medo e terror durante os suplícios físicos não eram vivenciados somente pelas vítimas diretas, mas estendiam-se aos seus familiares, seu entorno social e, muitas vezes, a toda a sociedade. Este efeito multiplicador do terror foi uma situação explorada e incentivada pela ditadura civil-militar devido ao seu alto grau de rentabilidade para o sistema repressivo, e foi conseguida, na maioria das vezes, através de certa publicidade das práticas terroristas combinada com a clandestinidade e a negativa da existência das mesmas.

Ao tomarem conhecimento de que seus entes estavam sendo torturados através da denúncia de companheiros, por visitas aos locais de detenção ou por cartas dos próprios encarcerados, os familiares iniciavam um longo processo de buscas, denúncias e pedidos de ajuda que visavam garantir o término das torturas e a integridade física de seus parentes.

A prática da tortura durante a ditadura civil-militar gerou uma série de ameaças à vida, que foram experimentadas de diversas formas. Primeiramente, como uma ameaça física: de abuso sexual, espancamento, tortura ou morte. Posteriormente, como uma ameaça psicológica, como as chantagens em estender as violências físicas aos demais membros do grupo familiar. Em terceiro lugar, e não diretamente relacionado à ação repressiva, como uma ameaça econômica, ou seja, o temor ao desemprego ou à incapacidade de ganhar o suficiente para atender às necessidades básicas suas e de sua família. Por último, pode ser sentida como um ataque aos valores do indivíduo, de modo que impeça a pessoa de viver sua vida de acordo com suas próprias crenças e premissas.

Esta mudança no comportamento e nos ideais e valores dos indivíduos - que resulta dos mecanismos de controle - é uma evidência do terrorismo empregado pelo Estado, que difundia normas imprecisas sobre o que era

${ }^{24}$ Ibid., p. 34. 
lícito ou não durante a ditadura. A imprecisão das leis e normas favoreceu a criação de um ambiente de terror, marcado pela ansiedade - uma "cultura do medo".

Entende-se por "cultura do medo", termo cunhado pelo cientista político argentino Guillermo O’Donnell ${ }^{25}$ uma situação de apatia oriunda do efeito dissuasivo e persuasivo do medo, que faz com que amplos setores da população passem a aceitar como "normais" situações previamente inaceitáveis $^{26}$.

\section{Atransição politica eocaminho para a continuidade do emprego da tortura}

Como afirmado anteriormente, durante a vigência da ditadura civil-militar, as violações aos direitos humanos foram consideradas pelas autoridades militares como "excessos", ou seja, não havia autorização, conhecimento ou ordens se seus superiores para a execução de tais atos delitivos, e os que assim agiram, estavam à margem do aparato repressivo. Esse argumento exculpante permanece legítimo nos meios militares até os dias de hoje, e se torna público quando é necessário justificar um crime como a tortura.

Mesmo com essas ressalvas, a elite civil e militar responsável pela transição política procurou manter o processo sob absoluto controle, para evitar qualquer ação de responsabilização penal ou simbólica pelos crimes

\footnotetext{
${ }^{25}$ Para um detalhamento da historiografia desse termo, conferir a resenha dessa obra realizada pela autora, que foi publicada pela revista História, imagens e narrativas. Cf. BAUER, Caroline Silveira. Medo, terrorismo de Estado e as ditaduras civil-militares de segurança nacional do Cone Sul. Resenha do livro: CORRADI, Juan E.; FAGEN, Patricia Weiss; GARRETÓN, Manuel Antonio (eds.). Fear at the edge: state terror and resistance in Latin America. Berkeley: University of California Press, 1992. 301 p. História, Imagem e Narrativas, v.4, 2007.

${ }^{26}$ CORRADI, Juan E.; FAGEN, Patricia Weiss; GARRETÓN, Manuel Antonio (eds.). Fear at the edge: state terror and resistance in Latin America. Berkeley: University of California Press, 1992. p. 3.
} 
cometidos nos anos anteriores. Estabeleceu-se, desta forma, uma relação de tutela amistosa entre civis e militares - um pacto -, que resultou na manutenção "de enclaves autoritários dentro do aparelho do Estado"27

O estabelecimento das novas relações entre esses grupos passariam, obrigatoriamente, pelo esquecimento dos crimes cometidos - segundo a lógica perversa da "ideologia da reconciliação", que forçosamente decreta o fim dos conflitos prévios a partir da compreensão de que "houve violência dos dois lados", logo, todos são culpados, equiparando a violência do Estado com a violência revolucionária -, e uma das primeiras medidas para concretizá-lo foi a promulgação da Lei de Anistia, de 28 de agosto de 1979.

Embora se trate de uma medida jurídica que impede o processamento penal, instituindo um perdão punitivo, essa lei, ao conceder anistia recíproca, estabelecia o controle do passado a partir de sua interdição, vetando o direito à verdade e, por consequência, o conhecimento dos fatos imbrincados com a ditadura civil-militar. $\mathrm{O}$ direito à verdade, assim, não era necessário, pois se considerava a ditadura "página virada" e, em última instância, uma ameaça à possibilidade de reciprocidade à anistia.

A anistia recíproca, convalidando a lógica da "ideologia da reconciliação", recupera outras características da formação social brasileira, como o "estigma da "Raízes do Brasil", Zilda Iokoi afirma que a cordialidade tornou-se um impeditivo das disputas por direitos e uma ameaça à consolidação da democracia, tentando-se neutralizar conflitos e disputas através de uma representação de conciliação e passividade. Todos aqueles que se opuseram aos caminhos da transição brasileira, foram considerados radicais e revanchistas, não entenderam que se vivia em um clima de transição e lhes acusavam de desconhecer as virtudes conciliatórias dos brasileiros ${ }^{28}$.

${ }^{27}$ ZAVERUCHA, Jorge. Rumor de sabres: controle civil ou tutela militar? São Paulo: Ática, 1994. p. 10.

${ }^{28}$ IOKOI, Zilda Márcia Gricoli. A longa transição de conciliação ou estigma da cordialidade: democracia descontínua e de baixa intensidade. In: SANTOS, Cecília Macdonell, TELES, Edson, TELES, Janaína de Almeida (orgs.). Desarquivando a ditadura: memória e justiça no Brasil. São Paulo: Hucitec, 2009. 2 v. p. 501-502. 
Pela permanência de políticas de desmemória e esquecimento fomentadas durante a ditadura, bem como pela configuração de uma relação entre civis e militares de tutela amistosa - manutenção da autonomia militar e/ou enclaves autoritários dentro do aparelho do Estado ${ }^{29}$-, pode-se afirmar que a transição política caracterizou-se por uma série de aspectos de continuidade em relação às violações de Direitos Humanos - seja na permanência de práticas e instituições, ou na omissão de investigações. De acordo com Zilda Iokoi, tratou-se de uma "transição metaforizada", indicativa de uma retórica de mudança sem mudanças ${ }^{30}$. Foi um processo pactuado, onde os onze longos anos do processo de abertura "lenta, gradual e segura" contribuíram sobremaneira para a diluição das responsabilidades, bem como para postergar as obrigações do Estado brasileiro em relação às violações de Direitos Humanos.

A longa duração da ditadura civil-militar brasileira contribuiu para a permanência da burocracia de Estado e o sistema judicial, "socializando uma classe de funcionários públicos nos valores da ditadura e criando novas elites favorecidas pelas políticas do regime". Essa institucionalização contribuiu para dificultar a estigmatização da ditadura. Neste sentido, as políticas de memória que se pretendiam teriam que ser implementadas por agentes estatais que poderiam se identificar ideologicamente com a ditadura, criando uma resistência ${ }^{31}$. Também contribuiu para a diluição da memória sobre os "anos de chumbo". De acordo com Jorge Zaverucha, a longa transição brasileira resultou de uma decisão deliberada, com finalidades de controlar o processo, fato evidenciado, também, pela aprovação no Congresso Nacional de um mandato de cinco anos para o primeiro presidente civil que seria eleito indiretamente ${ }^{32}$.

${ }^{29}$ ZAVERUCHA, Jorge. Op. cit., p. 10.

${ }^{30}$ IOKOI, Zilda Márcia Gricoli. Op. cit., p. 501.

${ }^{31}$ BRITO, Alexandra Barahona de. Justiça transicional e uma política da memória: uma visão global. MINISTÉRIO DA JUSTIÇA. Anistia Política e Justiça de Transição, n. 1, jan/jun 2009, p. 67.

${ }^{32}$ ZAVERUCHA, Jorge. Op. cit., p. 17. 
Assim, as demandas por memória, verdade e justiça foram administradas de acordo com a "lógica da protelação"33, repetida pelas administrações civis, onde "la espera del paso del tiempo para la resolución de los problemas del pasado, la espera de la extinción del problema a través del deceso tanto de los culpables como de los afectados. Esto es lo que hará que el conflicto se supere definitivamente." ${ }^{34}$

Desta forma, pode-se afirmar que a tortura é um dos elos que relaciona o presente das práticas policiais com o passado ditatorial brasileiro. Não se trata de uma questão de fácil resolução - pois implica a responsabilidade criminal pelo terrorismo de Estado da ditadura, bem como a sociedade defrontar-se com sua faceta mais autoritária e violenta.

As consequências do terrorismo de Estado, acrescidas às dificuldades de sua simbolização e representação, e à ausência de medidas reparatórias e a imposição do esquecimento contribuíram para a persistência do passado no presente, ou seja, para que as situações-limites vivenciadas não fossem elaboradas, e suas experiências e memórias ficassem reclusas aos círculos sociais das vítimas e seus familiares, em um processo de privatização da memória. A irresolução deste passado e sua perpetuação no presente é um dos motivos porque se afirma que a ditadura brasileira é "um passado que não passa." ${ }^{35}$

A Constituição promulgada em 1988 ficou conhecida como "Constituição cidadã" devido ao tratamento progressista dado a muitos temas, que garantiram direitos civis, políticos e sociais.

${ }^{33}$ D'ARAÚJO, Maria Celina, CASTRO, Celso. Introdução. In: D’ARAÚJO, Maria Celina, CASTRO, Celso (orgs.). Democracia e Forças Armadas no Cone Sul. Rio de Janeiro: FGV, 2000. p. 13.

${ }^{34}$ VINYES, Ricard. La memoria del Estado. In: VINYES, Ricard (ed.). El Estado y la memoria: gobiernos y ciudadanos frente a los traumas de la historia. Barcelona: RBA, 2009. p. 26.

${ }^{35}$ Esta expressão é retirada do título da obra de Eric Conan e Henri Rousso, Vichy, un passé qui ne passe pas, sobre a ocupação nazista na França e o colaboracionismo da sociedade francesa. Cf. CONAN, Eric, ROUSSO, Henri. Vichy, un passé qui ne passe pas. Paris : Seuil, 1996. 
Porém, no caso das relações entre civis e militares, não houve um profundo questionamento quanto ao legado autoritário da ditadura, permitindo que se mantivessem prerrogativas militares não democráticas oriundas da Constituição de 1967 e sua Emenda de 1969, principalmente relacionadas às Forças Armadas, às polícias militares estaduais e à segurança pública em geral. Uma das principais preocupações era a responsabilização penal daqueles que haviam violado os direitos humanos durante o período discricionário; preocupava-se que não houvesse uma "argentinização do regime" ${ }^{\text {"36 }}$ ou seja, que os militares brasileiros não fossem julgados no período democrático - à exemplo do que ocorreu na Argentina com os comandantes das Juntas Militares após o processo de transição política. "Isto porque existia a preocupação do "aprendizado por contágio", onde "sociedades que estão conduzindo processos de democratização podem fazer uso dos saberes ou do know-how adquirido de outras transições prévias" ${ }^{\text {"37. }}$. Esta teria sido, inclusive, uma das promessas do presidente indiretamente eleito, Tancredo Neves, às Forças Armadas: a "síndrome de Alfonsín" não atingiria a transição brasileira ${ }^{38}$.

$\mathrm{Na}$ verdade, figuras diretamente ligadas à ditadura, sejam elas civis ou militares, estiveram diretamente envolvidas no processo de elaboração da Constituição. De acordo com Jorge Zaverucha, os militares vetaram a possibilidade de uma Assembleia Nacional Constituinte como órgão elaborador da nova Carta. Receosos com os rumos da incipiente democracia brasileira, permitiram a existência de uma Constituinte formada pelos membros eleitos para o existente Congresso ${ }^{39}$

\footnotetext{
${ }^{36}$ BORGES, Nilson. A doutrina de segurança nacional e os governos militares. In: FERREIRA, Jorge, DELGADO, Lucilia de Almeida Neves (orgs.). O Brasil republicano - O tempo da ditadura: regime militar e movimentos sociais em fins do século $X X$. Rio de Janeiro: Civilização Brasileira, 2003. v. 4. p. 23.

${ }^{37}$ BRITO, Alexandra Barahona de. Op. cit., p. 70.

${ }^{38}$ ZAVERUCHA, Jorge. Op. cit., p. 96.

${ }^{39}$ ZAVERUCHA, Jorge. Relações civil-militares: o legado da Constituição brasileira de 1988. In: TELES, Edson, SAFATLE, Vladimir (orgs.). O que resta da ditadura: a exceção brasileira. São Paulo: Boitempo, 2010. p. 44.
} 
Assim, a Comissão de Organização Eleitoral Partidária e Garantia das Instituições, que ficou responsável pela elaboração dos capítulos referentes às Forças Armadas e à segurança Pública, foi presidida pelo senador Jarbas Passarinho "coronel da reserva, que serviu como ministro nos governos dos generais Costa e Silva, Médici e Figueiredo" e que foi um dos signatários do Ato Institucional n. 5, que institucionalizou o terrorismo de Estado no Brasil $^{40}$.

Além disto, realizaram lobby com os congressistas para que não houvesse mudanças substanciais no ordenamento das Forças Armadas brasileiras.

As Forças Armadas brasileiras entenderam tão competentemente a importância das restrições legais que nomearam 13 oficiais superiores para fazerem lobby pelos interesses militares ante os constituintes. Este lobby era muito bem organizado, chegando a levar os congressistas para visitas às instalações militares em todo o país ${ }^{41}$

$\mathrm{O}$ resultado destas articulações foi a reunião, no mesmo Título $\mathrm{V}-\mathrm{Da}$ Defesa do Estado e das Instituições, capítulos referentes à defesa, ao Estado de sítio, às Forças Armadas e à segurança pública. Segundo Zaverucha,

Nossos constituintes não conseguiram se desprender do regime autoritário recém-findo e terminaram por constitucionalizar a atuação de organizações militares em atividades de polícia (Polícia Militar) e defesa civil (Corpo de Bombeiros), ao lado das polícias civis. As polícias continuaram constitucionalmente, mesmo em menor grau, a defender mais o Estado do que o cidadão ${ }^{42}$

Porém, e mais diretamente relacionado ao tema da tortura, está a manutenção da estrutura do aparelho policial criado durante a ditadura civil-militar. Considerando-se que o modelo de segurança pública foi estruturado em um período autoritário, não haveria como esperar práticas democráticas em instituições que não correspondem ao Estado de direito democrático. Deste ponto de vista, evidencia-se porque a tortura continuou

\footnotetext{
${ }^{40}$ Ibid., p. 46.

${ }^{41}$ Ibid., p. 45.

${ }^{42}$ Ibid., p. 55. 
sendo praticada mesmo após o fim da ditadura: toda a estrutura de segurança pública permitia a continuidade das práticas repressivas de terror de Estado.

Em outras palavras, pode-se afirmar que a segurança pública pós-ditadura continuou regida pela lógica da doutrina de segurança nacional, que orientou ideologicamente as ditaduras de segurança nacional do Cone Sul.

Apesar da nova fase de democracia formal, apesar da promulgação da Constituição Federal de 1988, apesar do ocaso da Doutrina de Segurança Nacional, e apesar da derrogação da Lei de Segurança Nacional, suas marcas ainda pesam como tristes pegadas que deixam um norte para um caminho autoritário. Em suma, podemos dizer que não existe, no Brasil, uma concepção de segurança pública para o Estado Democrático de Direito. [...] O entendimento de Segurança Pública, expresso nas doutrinas e nas práticas dos vários órgãos no Brasil, ainda está fundamentado na antiga Doutrina de Segurança Nacional que valeu no país nos tempos autoritários. Isto significa que permanecemos, após a Constituição de 1988, sem uma concepção de Segurança Pública para o Estado Democrático de Direito, tanto em nível federal, quanto nos estadual e municipal ${ }^{43}$

Desta forma, pode-se apontar um grave problema para a construção da cidadania na democracia incipiente. A falta de garantia para os direitos civis ficou explícita no que se refere à segurança individual, à integridade física e ao acesso à justiça em se tratando de possíveis atos de violência praticados pelas forças de segurança brasileiras.

A questão da segurança apresenta outra peculiaridade de consequências sociais graves - não somente traduzida por suas práticas, como ainda pelas leis penais vigentes e tendências judiciais dela decorrentes -, qual seja, seus objetivos primeiros de defender o Estado e o patrimônio, deixando os cidadãos em segundo plano, quando não, para nossa perplexidade e indignação, são encarados como inimigos da ordem pública ${ }^{44}$

\footnotetext{
${ }^{43}$ DISTRITO FEDERAL. Secretaria de Segurança Pública. Segurança pública e democracia: a segurança pública como instrumento para a prática da cidadania e da organização social da liberdade. Brasília, maio de 1997. p. 6-7.

${ }^{44}$ DISTRITO FEDERAL. Secretaria de Segurança Pública. Segurança pública e democracia: a segurança pública como instrumento para a prática da cidadania e da organização 
Tome-se como exemplo a manutenção das polícias militares estaduais. Durante a ditadura, essa instituição esteve sob comando de oficiais do Exército, que militarizaram ainda mais o treinamento dos agentes. Sua ação foi direcionada para o "combate à subversão", e se utilizou órgãos de inteligência e repressão próprios que atuavam conjuntamente às Forças Armadas ${ }^{45}$.

Com a promulgação da Constituição de 1988, a única modificação quanto à estrutura da corporação foi seu controle, que passou do Exército para os governadores dos estados. Não houve mudanças efetivas na organização, no treinamento e na ação da polícia militar, o que possibilitou a continuidade de práticas como a tortura.

Nas palavras do sociólogo José Murilo de Carvalho.

Elas [as polícias militares] permaneceram como forças auxiliares e reservas do Exército e mantiveram as características militares. Tornaram-se novamente pequenos exércitos que às vezes escapam do controle dos governadores. Essa organização militarizada tem-se revelado inadequada para garantir a segurança dos cidadãos. O soldado da polícia é treinado dentro do espírito militar e com métodos militares. Ele é preparado para combater e destruir inimigos e não para proteger os cidadãos. Ele é aquartelado, responde a seus superiores hierárquicos, não convive com os cidadãos que deveria proteger, não os conhece, não se vê como garantidor de seus direitos. Nem no combate ao crime as polícias militares têm se revelado eficientes. Pelo contrário, nas grandes cidades e mesmo em certos estados da federação, policiais militares e civis têm-se envolvido com criminosos e participado de um número crescente de crimes. Os que são expulsos da corporação se tornam criminosos potenciais, organizam grupos de extermínio e participam de quadrilhas. Mesmo a polícia civil, que não tem treinamento militarizado, se vem mostrando incapaz de agir dentro das normas de uma sociedade democrática. Continuam a surgir denúncias de prática de tortura de suspeitos dentro das delegacias, apesar das promessas de mudanças feitas pelos

social da liberdade. Brasília, maio de 1997. p. 7-8.

${ }^{45}$ CARVAlHO, José Murilo de. Cidadania no Brasil: o longo caminho. Rio de Janeiro: Civilização Brasileira, 2003. p. 212-213. 
governos estaduais. São também abundantes as denúncias de extorsão, corrupção, abuso de autoridade feitas contra policiais civis ${ }^{46}$

Assim, não somente a sociedade pode vir a sofrer as consequências de um treinamento militarizado onde a tortura é sinônimo de "fortalecimento de caráter", como foi demonstrado no primeiro produto. Os próprios militares são vítimas dessas práticas em seus treinamentos. O Grupo Tortura Nunca Mais do Rio de Janeiro e o Centro de Justiça Global realizaram uma denúncia ao Comitê Contra a Tortura da ONU, em maio de 2001, relatando 11 casos de torturas, mortes e suicídios no período 1991-2001 em consequência dos tipos de treinamentos realizados.

Organizações e defensores de Direitos Humanos encaminharam propostas para a Constituinte para que fossem incorporados no texto da Constituição os tratados internacionais de proteção e defesa dos Direitos Humanos, bem como emendas que tivessem por objetivo a criminalização da tortura.

A temática da tortura suscitou mais de 150 propostas de emenda ao projeto de texto constitucional, apresentadas em várias fases entre os anos de 1987 e 1988. Algumas seguiam os preceitos das convenções e jurisprudência internacionais de direitos humanos acerca da tortura, considerando-a crime de lesa humanidade quando sistemática ou disseminada, outras formulações procuravam criar obstáculos à introdução do tema na Constituição. Ao final, o texto constitucional acolheu a versão mais genérica e difusa de proibição da tortura, sem a preocupação de delimitar conceitos. ${ }^{47}$

Desta forma, a Constituição foi promulgada estabelecendo no artigo $5^{\circ}$, Título II "Dos direitos e garantias fundamentais", inciso III, que "ninguém será submetido à tortura nem a tratamento desumano ou degradante." Ainda, estabeleceu que o crime de tortura era inafiançável e inanistiável, bem como reconheceu, como integrantes do direito constitucional, os tratados internacionais de proteção e defesa dos direitos humanos.

${ }^{46}$ Ibid., p. 213.

${ }^{47}$ JESUS, Maria Gorete Marques de, FILHO, José de Jesus. Uma década é pouco: tortuosos caminhos para a consolidação de uma política de combate e prevenção da tortura no Brasil. In: NÚCLEO de Estudos da Violência. $5^{\circ}$ Relatório Nacional sobre Direitos Humanos no Brasil-2001-2010. São Paulo: NEV, 2012. p. 91. 
Apesar de ser diretamente citada no texto constitucional como um crime, sua efetiva criminalização ocorreu somente passados quase 10 anos, com a aprovação da Lei n. 9.455 de 1997.

A proposta de lei, vinda do Executivo, foi aprovada às pressas pela Câmara e pelo Senado,

trazendo consigo uma série de elementos que a tornam ambígua, ao fragmentar o crime de tortura em vários tipos penais, incorporar elementos estranhos ao conceito proposto pelos documentos internacionais, ignorar outros de suma relevância como o propósito de discriminação por orientação sexual e transformá-la em crime comum, sem oferecer uma definição precisa do que vem a ser tortura. Não se sabe se o legislador optou por fazer uma lei mais genérica, cuja responsabilidade de definições ficasse a critério do intérprete da lei, o que é todo inaceitável, ou se ela foi realizada sem muitos cuidados, [...]. Além disso, a Lei também não previu políticas de combate e prevenção à tortura, como também não consagrou outros aspectos importantes para o enfrentamento da tortura no Brasil e que dizem respeito à tortura psicológica. ${ }^{48}$

Além disso, outros dispositivos jurídicos como o Código Penal, a Lei de Execução Penal e o Código de Processo Penal proíbem a prática de tortura em todo o território nacional"49. A tortura também é considerada um crime contra a humanidade "quando os atos são perpetrados como parte de um ataque generalizado ou sistemático contra a população civil, quando são cometidos ou não no curso de um conflito armado"50.

Retomando, em 1988, foi promulgada no Brasil uma nova Constituição, que garantia em seu texto o direito de qualquer cidadão brasileiro de ter informações sobre sua pessoa, o chamado habeas data - um dos componentes do direito à verdade. Porém, em relação à temática militar,

\footnotetext{
${ }^{48}$ Ibid., p. 93.

${ }^{49}$ BRASIL. Presidência da República. Resposta do governo brasileiro às recomendações do Subcomitê de prevenção da tortura da Organização das Nações Unidas. Brasília, outubro de 2012. p. 5.

${ }^{50}$ FOLEY, Conor. Protegendo os brasileiros contra a tortura. Ministério das Relações Exteriores Britânico e Embaixada Britânica no Brasil, 2011. p. 20.
} 
pouca coisa foi alterada: não foram extintos o SNI e suas ramificações nos ministérios e autarquias federais, não foi criado o Ministério da Defesa, órgão que permitiria um controle civil sobre as Forças Armadas, dentre outras medidas. De acordo com Jorge Zaverucha, "os militares deixaram de ser governo, mas continuaram no poder" "51, ou seja, sua política em relação ao passado seria a mesma deixada pelos governos transicionais, e reproduzida pelas administrações democráticas através da "lógica da protelação". À época da promulgação da Constituição, o então presidente José Sarney declarou: "O Exército é hoje um dos mais fortes pilares de nossa transição para a democracia" 52 . Na mesma linha, o então chefe do Estado Maior das Forças Armadas, general Waldir Eduardo Martins, em visita ao Chile, governado por Pinochet, afirmou em uma entrevista ao jornal El Mercurio: "O Exército chileno constitui um exemplo para a América Latina" 53.

A ausência de controle civil sobre os militares, assim como a não condenação do passado ditatorial brasileiro, permitiu que nos anos seguintes, uma série de militares permanecessem em cargos oficiais ou fossem condecorados pelos serviços prestados nos anos precedentes. Por citar apenas um exemplo de cada caso, lembre-se o episódio envolvendo Carlos Alberto Brilhante Ustra, acusado de torturar no DOI-CODI, como adido militar na embaixada do Brasil no Uruguai, reconhecido, em 12 de agosto de 1985, por Bete Mendes, como seu torturador, em uma solenidade oficial; ou Dalmo Lúcio Muniz Cyrillo, subcomandante da OBAN, capitão de artilharia à época, era acusado como responsável pela morte de Joaquim Alencar de Seixas. Por decreto de 18 de junho de 1993, publicado no Diário Oficial de 21 de junho de 1993, foi condecorado como cavaleiro "em razão dos relevantes serviços prestados à nação e às Forças Armadas" ${ }^{54}$.

${ }^{51}$ ZAVERUCHA, Jorge. Rumor..., op. cit., p. 11.

${ }^{52}$ ZAVERUCHA, Jorge. Relações...,, op. cit., p. 186.

${ }^{53}$ Ibid., p. 192.

${ }^{54}$ COMPARATO, Fábio Konder. Ética política e honra militar. In: TELES, Janaína (org.). Mortos e desaparecidos políticos: reparação ou impunidade? São Paulo: Humanitas, 2001. p. 37. 


\section{Tortura, democracia e Estado de direito}

Paralelamente ao processo de transição política descrito acima, a garantia dos direitos civis com a mudança de regime político permitiu que surgissem ou se fortalecessem muitas organizações da sociedade civil, entre elas, as envolvidas com a temática dos Direitos Humanos. Algumas delas, como o Movimento Nacional de Direitos Humanos, passaram a receber denúncias de casos de tortura.

A constatação de que os Direitos Humanos seguiam sendo violados após a ditadura possibilitou que essas organizações pudessem realizar denúncias e exigir políticas públicas, ratificação de instrumentos internacionais sobre a tortura e a promulgação da Lei n. 9.455, de 7 de abril de 1997, que define, tipifica e estabelece a punição para o crime de tortura.

Os primeiros dados a serem analisados provêm do SOS-Tortura. Durante o período compreendido entre 30 de outubro de 2001 e 30 de outubro de 2002, foram registradas 23.709 ligações, das quais 1.629 foram denúncias de tortura.

Os números apontam que as delegacias de política são os espaços privilegiados para a tortura, evidenciando que a prática ainda é institucional. Por consequência, os policiais são apontados como os principais agentes de tortura, o que poderia significar: a) uma continuidade de quadros oriundos da ditadura civil-militar; b) uma formação que considere a tortura como prática legítima.

Quanto ao perfil da vítima, este corresponde a jovens, entre 19 e 29 anos, do sexo masculino. Quanto à etnia, mesmo que 35,38\% das vítimas não tenham informado a cor de sua pele, $39,31 \%$ das denúncias são de pessoas de pele parda ou negra.

Ampliando o escopo da pesquisa, a Comissão de Direitos Humanos e Minorias da Câmara dos Deputados divulgou em 2005 novos dados provenientes do SOS-Tortura. Este serviço, entre 31 de outubro de 2001 e 31 de janeiro de 2004, recebeu 1.863 denúncias de tortura e tratamento cruel, desumano ou degradante. A tabela abaixo demonstra a distribuição das denúncias pelas unidades federativas brasileiras. 
Tabela 1: Distribuição das denúncias pelas unidades federativas brasileiras ${ }^{55}$

\begin{tabular}{|c|c|}
\hline Estado & Número de denúncias \\
\hline São Paulo & 306 \\
\hline Minas Gerais & 283 \\
\hline Pará & 168 \\
\hline Bahia & 145 \\
\hline Rio de Janeiro & 96 \\
\hline Distrito Federal & 82 \\
\hline Maranhão & 74 \\
\hline Pernambuco & 72 \\
\hline Paraná & 71 \\
\hline Tocantins & 70 \\
\hline Goiás & 60 \\
\hline Ceará & 51 \\
\hline Rio Grande do Norte & 41 \\
\hline Espírito Santo & 41 \\
\hline Mato Grosso do Sul & 34 \\
\hline Rondônia & 34 \\
\hline Amazonas & 33 \\
\hline Parabía & 32 \\
\hline Rio Grande do Sul & 32 \\
\hline Santa Catarina & 30 \\
\hline Alagoas & 30 \\
\hline Mato Grosso & 28 \\
\hline Piauí & 18 \\
\hline Sergipe & 15 \\
\hline Acre & 8 \\
\hline Amapá & 4 \\
\hline Roraima & 3 \\
\hline
\end{tabular}

Dentre os diversos motivos que levam os agentes de segurança a torturarem pessoas que estejam sob sua custódia, os que possuem maior registro

${ }^{55}$ Analisando-se os dados de 2005, da Comissão de Direitos Humanos e Minorias da Câmara dos Deputados, pode-se traçar um perfil da prática da tortura nos dias de hoje. Esses dados provêm do SOS Tortura. 
são a tortura com a finalidade de castigar os custodiados (38\%) e para obter informações (33\%). A tabela abaixo demonstra a totalidade dos casos.

Tabela 2: Principais motivos para a utilização da tortura

\begin{tabular}{c|c|c}
\hline Motivação & Número de denúncias & Porcentagem \\
\hline Forma de castigo & 724 & $38 \%$ \\
\hline $\begin{array}{c}\text { Obter confissão ou } \\
\text { informação }\end{array}$ & 607 & $33 \%$ \\
\hline Não informado & 219 & $12 \%$ \\
\hline Intimidação & 161 & $9 \%$ \\
\hline Outros & 146 & $8 \%$ \\
\hline Discriminação & 6 & $0 \%$ \\
\hline
\end{tabular}

Quanto às dependências, a maior incidência de práticas de tortura ocorrem nas delegacias de polícia (40\%) e as unidades prisionais $(21 \%)$. A tabela abaixo mostra o universo total de análise.

Tabela 3: Locais onde ocorreram as denúncias de tortura

\begin{tabular}{c|c|c}
\hline Local & Número de denúncias & Porcentagem \\
\hline Delegacia & 730 & $40 \%$ \\
\hline Unidade prisional & 395 & $21 \%$ \\
\hline Outros & 328 & $18 \%$ \\
\hline Local deserto & 121 & $6 \%$ \\
\hline Não informado & 82 & $4 \%$ \\
\hline Residência & 70 & $4 \%$ \\
\hline $\begin{array}{c}\text { Unidade de internação de } \\
\text { adolescentes }\end{array}$ & 43 & $2 \%$ \\
\hline Batalhão da Polícia Militar & 36 & $2 \%$ \\
\hline Quartel & 21 & $1 \%$ \\
\hline Viatura & 17 & $1 \%$ \\
\hline Rua & 20 & $1 \%$ \\
\hline
\end{tabular}

Quanto aos agentes agressores, o maior número de denúncias recai sobre os policiais militares (53\%), que muitas vezes, cumprem a função de funcionários de prisão. Os dados abaixo demonstram esses números e outros 
Tabela 4: Agente agressor por alegação

\begin{tabular}{c|c}
\hline Agente agressor & Número de denúncias \\
\hline Polícia Militar & 1177 \\
\hline Polícia Civil & 1022 \\
\hline Funcionário de prisão & 287 \\
\hline Não informado & 146 \\
\hline Outros & 179 \\
\hline Funcionário de unidade de internação de \\
adolescentes & 52 \\
\hline Polícia Federal & 32 \\
\hline Criminoso & 15 \\
\hline Familiar & 3 \\
\hline Policial não identificado & 1 \\
\hline Outro funcionário & 1 \\
\hline
\end{tabular}

Quanto às vítimas, o perfil do "torturado" é adulto jovem, homem, negro, pobre e com baixo nível de escolaridade. A tabela abaixo demonstra o as características das principais vítimas.

Tabela 5: Principais vítimas da tortura

\begin{tabular}{c|c}
\hline & Número de denúncias \\
\hline Adulto & 1937 \\
\hline Adolescente & 288 \\
\hline Não informado & 249 \\
\hline Criança & 22 \\
\hline Outros & 11 \\
\hline Deficiente & 12 \\
\hline Gestante & 3 \\
\hline
\end{tabular}

Observação: a soma do número de denúncias e maior do que o total de alegações, já que já diversos casos com mais de uma vítima.

Mais recentemente, o Departamento de Ouvidoria Nacional de Direitos Humanos registrou, no período compreendido entre $1^{\circ}$ de janeiro de 2011 a 25 de junho de 2012, 1.694 denúncias referentes à tortura. Os Estados líderes em denúncias (absolutas) são São Paulo, Minas Gerais, Per- 
nambuco e Rio de Janeiro e com mais denúncias (por 100 mil habitantes) são Distrito Federal, Mato Grosso, Mato Grosso do Sul e Pernambuco"56. São praticamente nove casos de tortura denunciados todos os dias.

Segundo Cecília Coimbra, a prática da tortura é percebida pela sociedade, nos dias de hoje, como uma questão que não lhe diz respeito, ou, ainda, como um "mal necessário" para conter a violência de setores considerados "perigosos". Embora legítima, a defesa da tortura não necessariamente precisa ser feita publicamente para que se saiba de sua existência ${ }^{57}$. Praticada em dependências militares e policiais, em presídios e hospícios, e por agentes de segurança fora de seus ambientes de trabalho, a tortura permanece como uma constante na história brasileira, desde o período colonial, passando, no século XX, pela repressão ao movimento operário, durante a ditadura de Getúlio Vargas, e durante a ditadura civil-militar brasileira.

Nesse sentido, perpetua-se pelos agentes de segurança e pela sociedade, a compreensão do "inimigo" herdada da ditadura civil-militar. No período democrático, este "inimigo" não se tratava mais do opositor político - em todos os seus níveis -, mas aos "perigosos", aos "diferentes", aos "marginais", em outras palavras, aos excluídos sociais; segmentos pauperizados que sofrem cotidianamente a violação dos Direitos Humanos e rotulados como cidadãos sem direitos.

\footnotetext{
Em uma sociedade como a nossa, marcada muito mais pela hierarquia entre os cidadãos do que pelos valores da igualdade entre eles, há uma indisfarçável tolerância da parte de muitos grupos sociais (elites e classe média) com relação à tortura, uma vez que ela atinge pobres, moradores de áreas urbanas degradadas, negros, criminosos - afeta, enfim, os que não chegam a ser vistos por aqueles grupos como cidadãos portadores de direitos. O desdobramento dessa tolerância é uma acomodação política. Os partidos e as plataformas de governo, em sua maioria, repudiam oficialmente a tortura e os maus-tratos, mas não concentram de fato
}

\footnotetext{
${ }^{56}$ BRASIL. Presidência da República. ...2012. Op. cit., p. 56.

${ }^{57}$ COIMBRA, Cecília Maria Bouças. Tortura ontem e hoje: resgatando uma certa história. Psicologia em Estudo, Maringá, v. 6, n. 2, p. 11-19, jul./dez. 2001. p. 12.
} 
muitos esforços para reverter a situação, especialmente os governos estaduais, responsáveis diretos pela manutenção das polícias e do sistema prisional $^{58}$

Essa indissociável relação entre pobreza e periculosidade foi construída historicamente no Brasil, tendo suas origens em instituições como a escravidão e práticas correlatas. "O extermínio dos subalternizados tem sido plenamente justificado como uma necessária "limpeza social", aplaudido pelas elites e por muitos segmentos médios de nossa sociedade. Como no período da ditadura militar, também hoje, nesses tempos neoliberais, o 'inimigo interno' deve ser não somente calado, mas também exterminado" 59 .

Michel Foucault assinala em "Vigiar e Punir" que, no final do século XVIII e início do século XIX, houve um deslocamento do objeto de punição: do corpo para a alma dos indivíduos. E, da mesma forma, nessa "sociedade punitiva", tornou-se necessário controlar "o coração, o intelecto, a vontade e as disposições",60, pré-determinando sujeitos "mais propensos" ao delito - o dispositivo da periculosidade: "ex-escravo, negro, mestiço, índio, migrante, pobre, favelado, morador de periferia, analfabeto. Inaugura-se a era da periculosidade, na qual determinados segmentos por sua natureza deverão ser constantemente vigiados, disciplinados, normatizados"61.

Devido às características de continuidade da transição política brasileira, como apontado anteriormente - principalmente a ausência de uma "sanitização do Estado" - a tortura segue sendo utilizada como uma política sistemática do Estado brasileiro. "Não se trata, portanto, apenas de omissão, conivência e/ou tolerância por parte das autoridades e da sociedade em geral para com tais questões, mas de uma política silenciosa, não falada, que aceita e mesmo estimula esses perversos procedimentos" ${ }^{\prime \prime}$.

\footnotetext{
${ }^{58}$ PIOVESAN, Flávia, SALLA, Fernando. Ciência Hoje, v. 30, n. 176, p. 32.

${ }^{59}$ COIMBRA, Cecilia Maria Bouças. Op. cit., p. 18.

${ }^{60}$ FOUCAULT, Michel. Vigiar e punir. Petrópolis: Vozes, 1987. p. 21.

${ }^{61}$ COIMBRA, Cecilia Maria Bouças. Op. cit., p. 13.

${ }^{62}$ Ibid., p. 12.
} 
Em pesquisa realizada em 2009 pela agência Nova S/B, em parceria com o Ibope, $26 \%$ dos entrevistados declararam-se favoráveis à tortura de suspeitos, realizada por agentes policiais. Os quase quatro séculos de escravidão deixaram sua marca vil: nos entrevistados com renda mensal superior a cinco salários mínimos, o índice de aprovação da tortura policial chegou a $42 \%$, ao passo que a média de aprovação, entre os que vivem com menos de cinco salários mínimos de renda por mês, não ultrapassou 19\% (Comparato, 2010a, p. 109). Outra pesquisa, coordenada por Gustavo Venturi, revelou que um quinto da população brasileira conhece pessoalmente alguém que tenha sido torturado, mas apenas $12 \%$ consideram a tortura uma prática que deve ser combatida (Arantes e Pontual, 2010, p. 49) ${ }^{63}$

No entanto, a tortura não poderia ser justificada de nenhuma forma. De acordo com Conor Foley,

A proibição absoluta da tortura e dos maus tratos é ressaltada pelo caráter não derrogável dos direitos humanos. Não há circunstâncias nas quais os Estados podem colocar de lado ou restringir essa obrigação, inclusive em tempos de guerra, ameaças terroristas ou outras emergências que ameaçam a vida da nação e que possam justificar a suspensão ou limitação de alguns outros direitos. Os Estados também são proibidos de fazer derrogações que possam colocar indivíduos em risco de tortura ou maus tratos - por exemplo, permitindo períodos excessivos de detenção incomunicada ou negando ao detento o acesso imediato a um tribunal. Esta proibição opera independentemente de circunstâncias ou atributos, tais como a condição da vítima, ou se ele ou ela é suspeito(a) de algum crime, seja qual for o crime que ele ou ela é suspeito (a) de ter cometido ${ }^{64}$.

Segundo Maria Rita Kehl, "a redemocratização custou à sociedade o preço do perdão aos agentes do Estado que torturaram, assassinaram e fizeram desaparecer os corpos de opositores da ditadura" A psicanalista faz uma provocação ao convidar os leitores a encarar o fato de que

\footnotetext{
${ }^{63}$ SOARES, Maria Victoria de Mesquita Benevides. Tortura no Brasil, uma herança maldita. In: BRASIL. Secretaria de Direitos Humanos. Coordenação Geral de Combate à tortura (org.). Tortura. Brasília: Secretaria de Direitos Humanos, 2010. p. 22.
}

${ }^{64}$ FOLEY, Conor. Op. cit., p. 18. 
a sociedade brasileira não está nem aí para a tortura cometida no país, tanto faz se no passado ou no presente. [...] A pesquisadora norte-americana Kathrin Sikking revelou que no Brasil, à diferença de outros países da América Latina, a polícia mata mais hoje, em plena democracia, do que no período militar. Mata porque pode matar. Mata porque nós continuamos a dizer tudo bem. [...] Pouca gente se sá conta de que a tortura consentida, por baixo do pano, durante a ditadura militar é a mesma que assistimos hoje, passivos e horrorizados. Doença grave, doença crônica contra a qual a democracia só conseguiu imunizar os filhos da classe média e alta, nunca os filhos dos pobres ${ }^{65}$

A análise dessas características sobre a transição política brasileira é fundamental para se compreender por que, ainda hoje, a tortura seja uma prática comum nas instituições policiais civis e militares.

Em primeiro lugar, é necessário fazer referência à impunidade que marcou todo o período ditatorial, foi corroborado com a promulgação da lei de anistia, e permanece no regime democrático pelas dificuldades na punição dos responsáveis pela prática da tortura.

De acordo com a Coordenação-Geral de Combate à tortura da Secretaria de Direitos Humanos da Presidência da República, os principais fatores que fomentam a cultura da impunidade são:

a) a resistência dos agentes públicos de denunciar e investigar casos praticados por colegas de profissão;

b) a resistência de diretores e gerentes das organizações do sistema de justiça criminal em admitir a tolerância da tortura em suas instituições;

c) o medo das vítimas e dos familiares de denunciar a tortura;

d) a percepção - ainda que equivocada - de parte dos agentes públicos e da população de que a prática de tortura produz benefícios imediatos do ponto de vista da obtenção de informações de suspeitos e criminosos e da manutenção da ordem em unidades de privação de liberdade ${ }^{66}$.

\footnotetext{
${ }^{65} \mathrm{KEHL}$, Maria Rita. Tortura, por que não? O Estado de S. Paulo, São Paulo, $1^{\circ}$ mai. 2010. ${ }^{66}$ BRASIL. Presidência da República. Secretaria de Direitos Humanos. Coordenação-Geral de Combate à tortura. Plano de ações integradas para a prevenção e o combate à tortura no Brasil. [s. d.]. p. 19.
} 
A mesma constatação foi feita pelo Subcomitê de Prevenção da Tortura (SPT), da Organização das Nações Unidas, em visita ao Brasil no ano de 2011. Conforme o relatório apresentado,

\begin{abstract}
A impunidade por atos de tortura está disseminada e se evidencia pelo fracasso generalizado em levar-se os criminosos à justiça, bem como pela persistência de uma cultura que aceita os abusos cometidos pelos funcionários públicos. Em muitas de suas reuniões, o SPT solicitou acesso ao número de indivíduos sentenciados pelo crime de tortura, mas o dado não foi fornecido. Os indivíduos entrevistados pelo SPT não demonstram esperança de que justiça fosse feita ou de que sua situação particular fosse considerada pelas instituições estatais ${ }^{67}$.
\end{abstract}

Segundo dados apresentados pelo Brasil ao Subcomitê apenas 160 pessoas haviam sido acusadas pelo crime de tortura no contexto de uma população carcerária de 512 mil detentos, para se restringir somente à população privada de liberdade, sem referência aos detentos provisórios, situações de abordagem policial, etc. ${ }^{68}$

Outras características da transição brasileira, como o alto grau de negociação e estabelecimento de pactos, somado à diluição da memória sobre a repressão no longo processo de construção da democracia, colaborou para que houvesse uma série de permanências institucionais, pessoais e de práticas no Estado brasileiro. Não houve, durante a mudança de regime político, uma "sanitização" do Estado, o que permitiu uma continuidade da ditadura na democracia.

Neste sentido, seria necessário um pacto entre os agentes de segurança para a erradicação da tortura como uma prática comum da ação policial:

Todos os funcionários públicos que tenham contato com pessoas detidas devem estar cientes da lei e devem ter sido devidamente treinados sobre o que ela significa na prática. Os detentos precisam estar cientes de seus

\footnotetext{
${ }^{67}$ ORGANIZAÇÃO das Nações Unidas. Subcomitê de prevenção da tortura e outros tratamentos ou penas cruéis, desumanos ou degradantes. Relatório sobre a visita ao Brasil do Subcomitê de prevenção da tortura e outros tratamentos ou penas cruéis, desumanos ou degradantes. 8 fev. 2012. p. 11.
}

${ }^{68} \mathrm{Idem}$. 
direitos, incluindo o direito de denunciar violações e de ter pronto acesso a um advogado ou qualquer outro mecanismo independente. Os juízes e promotores precisam entender suas próprias obrigações de não ser coniventes com técnicas opressivas de interrogatório ou aceitar como provas declarações que tenham sido obtidas por meio de coerção. Eles também têm a obrigação de procurar por sinais de sofrimento físico ou mental em qualquer pessoa que seja apresentada perante os mesmos, em levar todas as denúncias de maus tratos a sério, de realizar regularmente inspeções em locais de detenção e de impetrar ações contra os autores de violações ${ }^{69}$.

Da mesma forma, o Estado deveria empregar uma política de "tolerância zero" quanto à tortura, de acordo com o Subcomitê de Prevenção à Tortura:

O SPT recomenda que todas as alegações de tortura e de maus-tratos sejam rigorosamente investigadas, de modo rotineiro, e que os perpetradores sejam responsabilizados pelos seus atos. O Estado Parte deve emitir uma forte condenação, no mais alto nível, declarando que a tortura não será tolerada sob nenhuma circunstância. Essa mensagem de "tolerância zero" com relação à tortura e aos tratamentos desumanos deve ser encaminhada, em intervalos regulares, a todas as forças de segurança e equipes de custódia, inclusive por meio de treinamento profissional ${ }^{70}$.

Ainda quando às permanências, há todo um legado autoritário presente na legislação brasileira, do qual a lei de anistia é apenas um exemplo, podendo ser citada a lei de segurança nacional, etc. No Brasil, a política de esquecimento implementada com a lei de anistia teve continuidade nos governos civis através da "lógica da protelação", buscando acomodação e estabilidade - sustentando se a crença de que a melhor política de memória e reparação é aquela que não existe, ou que tarda muito para ser efetivada.

A impossibilidade de garantir o direito à justiça é, até os dias de hoje, um dos principais empecilhos para o fim da prática da tortura, já que fomenta uma cultura de impunidade e de desrespeito aos Direitos Humanos.

\footnotetext{
${ }^{69}$ FOLEY, Conor. Op. cit., p. 21-22.

${ }^{70}$ ORGANIZAÇÃO das Nações Unidas. Op. cit.. p. 11. 
O direito à justiça, concebido dentro do escopo da justiça de transição, tem uma dupla função: retroativa, modificando qualquer marco legal que o impeça de ocorrer; e em direção ao futuro, como prevenção para que não se repitam as graves violações aos direitos fundamentais do homem.

Nesse sentido, pode-se afirmar que, na prática, não houve uma vinculação explicita entre a vigência plena dos Direitos Humanos com a construção do Estado de Direito brasileiro, pois não houve um rompimento nem um corte simbólico com o passado ditatorial - o que se daria através de uma valorização positiva dos direitos humanos e um repúdio generalizado dos métodos repressivos ilegais. Resumindo, ainda não houve a possibilidade de construir uma reprovação social da ditadura civil-militar brasileira e de suas práticas, pois há uma carência de concepções de cidadania e valorização dos direitos do cidadão. Ninguém foi punido pelos crimes cometidos pelo Estado durante o período de 1964 a 1985; paradoxalmente, não se pode afirmar que exista um desconhecimento sobre esses crimes. Essas contradições contribuíram para que as novas leis, principalmente, a nova Constituição fosse um "peso morto" quanto às violações aos Direitos Humanos.

\section{Considerações Finais}

Foram apresentados, nos itens anteriores, a prática da tortura durante a ditadura civil-militar e as ações tomadas durante os governos transicionais que permitiram que continuasse sendo empregada no regime democrático, cercada de legitimidade pelos agentes das forças de segurança que a perpetram e por setores da sociedade que esperam resultados mais efetivos no que acreditam ser "o combate à criminalidade". A explicação para essa continuidade pode ser encontrada na forma como foi realizada a transição política brasileira, e seu perpetuamento, na ausência de contundentes políticas públicas de memória e de reparação, nos moldes da justiça de transição.

Como a tortura não foi uma prática cuja aplicabilidade começou com o golpe civil-militar de 31 de março de 1964, seria necessário desenvolver 
uma análise histórico-sociológica do autoritarismo e da violência que estão impregnados na cultura política e social no Brasil - que evidenciaria o tortuoso caminho para a construção de uma cidadania plena no Brasil, incluindo-se os direitos civis, políticos e sociais. No entanto, devido ao escopo da pesquisa, os argumentos que seguem referem-se às continuidades da ditadura civil-militar de 1964 na democracia.

Como afirmado anteriormente, a transição política - entendida enquanto "transição metafórica" - foi realizada sob o controle da elite civil e militar, preocupada com a possibilidade de responsabilização penal pelas violações aos direitos humanos. O controle do processo, evidenciado por sua longa duração - onze anos que concorreram para a diluição das responsabilidades -, e pela garantia da impunidade, caracterizaram a construção da democracia sem drásticas rupturas em relação ao passado ditatorial. Da mesma forma, não houve o afastamento de nenhum agente do Estado implicado em denúncias de torturas e outros crimes do quadro de servidores; e muitas instituições criadas durante a ditadura, ou que funcionavam ao seu serviço, seguiram atuantes no período democrático. Por fim, a questão da segurança pública na democracia foi tratada a partir de uma articulação entre os constituintes e as Forças Armadas. Assim, pode-se garantir, por exemplo, uma estrutura herdada da ditadura, bem como a manutenção das polícias militares.

Um outro aspecto a ser ressaltado diz respeito à ausência de contundentes políticas públicas de memória e reparação, nos moldes da justiça de reparação. O Estado brasileiro, nos últimos anos, tem se esforçado em elaborar políticas de memória e reparação, que, no entanto, tem se mostrado ineficientes no combate à tortura e ao desaparecimento, que seguem sendo práticas corriqueiras pelas forças de segurança.

Mesmo que o Estado incentive a educação em Direitos Humanos nos cursos de treinamento das polícias civis e militares - ratificando o Plano Nacional de Direitos Humanos - 3 (PNDH-3), cumprindo a sentença emitida pela Corte Interamericana de Direitos Humanos da Organização dos Estados Americanos, muitos setores têm se questionado sobre a efetividade 
da formação em direitos humanos em uma instituição, como a polícia militar, que, em sua natureza, não possui um viés democrático. Assim, voltou-se a discutir a questão da extinção desta força.

No dia 25 de maio de maio de 2012, o Conselho de Direitos Humanos da Organização das Nações Unidas, sugeriu a extinção da Polícia Militar no Brasil. Os membros que se pronunciaram a favor da medida afirmaram que a existência de uma policia militar, até os dias de hoje, era uma evidência e explicação da dificuldade do Estado brasileiro de se livrar de instituições não democráticas oriundas de períodos autoritário-ditatoriais. $\mathrm{O}$ jornal Folha de S. Paulo de 24 de julho de 2012 divulgou uma pesquisa do Ipea, onde $62 \%$ dos entrevistados afirmaram não confiar ou confiar pouco na Polícia Militar. Da mesma forma, 51,5\% dos entrevistados afirmaram que as abordagens de policiais militares são desrespeitosas e inadequadas.

No dia 20 de setembro, a proposta foi rejeitada. De acordo com a reportagem da Opera Mundi, do dia 20 de setembro, "Maria Nazareth Farani de Azevedo, embaixadora brasileira na sede da ONU em Genebra, explicou que a extinção da polícia militar viola a constituição nacional que prevê a existência de forças civis e militares. Em sessão nesta manhã no Conselho de Direitos Humanos, a diplomata disse que os policiais militares "são responsáveis pelo policiamento extensivo e pela preservação da ordem pública”.

Para o desenvolvimento de efetivas políticas de memória e reparação, seriam necessárias duas ações concretas pelo Estado brasileiro: o expurgo do serviço público de servidores envolvidos com a prática de tortura e uma declaração pública e oficial de repúdio à ditadura civil-militar e a continuidade de suas práticas.

Em relação às reformas institucionais, é necessário dissolver todas as instituições responsáveis pelas violações dos direitos humanos, mas, mais do que isso, reformar a base do ensino das forças de segurança, a fim de que se mudem as práticas perpetradas por esses agentes que, em ambos os países, ainda se assemelham com as ações perpetradas durante as ditaduras civil-militares. Assim, programas de depuração e saneamento administrativo são fundamentais para que pessoas responsáveis ou vinculadas com vio- 
lações dos direitos humanos sejam retiradas de seus cargos públicos. Desta forma, poder-se-ia estimular a confiança e a responsabilidade, restaurando a integridade das instituições do Estado.

Quanto à declaração pública de repúdio da ditadura e de suas práticas na democracia, a condenação moral da ditadura torna-se um dos componentes fundamentais para a ruptura com esse passado, pois legitima institucionalmente todas as políticas de memória instituídas e executadas pela democracia.

E, complementando as políticas de memória e reparação, seria necessária a garantia ao acesso à justiça em todos os casos de tortura ou violação dos direitos humanos. A construção da democracia não é uma decorrência natural do fim da ditadura: sociedades que saem de regimes ditatoriais necessitam transformar-se e abandonar determinadas instituições e práticas autoritárias para que haja democracias plenas. Em se tratando de temáticas que versem sobre a continuidade da ditadura, é imprescindível à garantia dos direitos à memória, à verdade e à justiça.

Neste sentido, é necessário discorrer sobre a importância e o significado do acesso ao "direito à justiça". O cumprimento desse direito assegura a responsabilização e certa função pedagógica.

A justiça é vista como uma arma contra o esquecimento, que pode com-
bater a 'amnésia social', a negação, o encobrimento, e várias formas
perniciosas de revisionismo que negam ou justificam as atrocidades do
passado. Também já se observou que os julgamentos servem para esta-
belecer princípios morais e atuam como uma espécie de 'teatro político'
oferecendo 'lições coletivas de justiça'71

${ }^{71}$ BRITO, Alexandra Barahona de. Op. cit., p. 77. 
